Proceedings of the International Symposium on Physics of Materials (ISPMA 14), September 10-15, 2017, Prague

\title{
Characterization of Commercially Pure Ti Powders Prepared by Cryogenic Milling
}

\author{
J. Kozlík*, J. StrRáský, P. Harcuba, I. Ibragimov and M. JaneČEK \\ Department of Physics of Materials, Faculty of Mathematics and Physics, Charles University, \\ Prague, Czech Republic
}

\begin{abstract}
Commercially pure Ti Grade 2 was prepared by cryogenic attritor milling in liquid argon under different processing conditions. Two types of milling balls: stainless steel milling balls and tungsten carbide balls were employed. The effect of processing parameters on particle size and morphology, contamination, and powder microhardness was investigated. The powder particles changed their shape from spherical to a disc/plate during milling. Reduction of particle size was only moderate, depended on time of milling and was enhanced by using tungsten carbide balls. Milling procedure increases concentration of oxygen and nitrogen, which is critical in case of titanium. Milling in liquid nitrogen is not feasible and processing conditions of milling in liquid argon must be carefully selected.
\end{abstract}

DOI: 10.12693/APhysPolA.134.783

PACS/topics: 81.05.Bx, 81.20.Ev, 81.40.Cd, 81.40.Ef

\section{Introduction}

Titanium is a promising material for advanced applications thanks to its high specific strength, excellent corrosion resistance and good biocompatibility. To overcome its poor machinability, powder metallurgy could be a viable alternative for cost-efficient manufacturing of parts with complex shapes.

In powder metallurgy, properties of powders such as particle size and morphology, contamination and microstructure are important because they affect the compaction and further processing as well as properties of final bulk products. Materials, when subjected to intensive plastic deformation, increase of dislocation density and grain refinement occurs. Ultra-fine grained (UFG) materials (with submicrometer grain size) exhibit superior properties [1]. Current research focuses mainly on bulk UFG materials produced by methods of severe plastic deformation (SPD), such as equal channel angular pressing [2] or high pressure torsion [3]. Nevertheless, UFG material can be also achieved by high-energy mechanical milling followed by appropriate compaction method [4-6].

During mechanical milling, powder particles are repeatedly fragmented and cold-welded together [7], which determines the final particle size. This is also accompanied by intensive plastic deformation of individual particles and grain refinement within them. To suppress recovery and dynamic recrystallization during milling, cooling to cryogenic temperatures (typically by liquid nitrogen (LN) or liquid argon (LAr)) can be employed leading to the reduction of powder crystallite size (measured by X-ray diffraction) to the order of tens of nanometers (e.g. for aluminium [8] and titanium and its alloys $[5,9,10])$.

*corresponding author; e-mail: Jiri.Kozlik@seznam.cz
In our previous study [11], liquid nitrogen was found to be unsuitable as a cooling agent, because CP Ti becomes seriously contaminated by nitrogen (up to $2.9 \mathrm{wt} \%$ of $\mathrm{N})$ resulting in its brittleness. This confirms the earlier results obtained in [4].

\section{Experimental methods}

Initial powder was commercially pure $\mathrm{Ti}$ powder (Grade 2) manufactured by gas atomization (TLS Technik GmbH, Germany). All handling was performed in air.

Union Process 01-HD attritor $\left(1400 \mathrm{~cm}^{3}\right)$ was used for powder milling in liquid argon slurry (wet milling). Stainless steel (SS) and tungsten carbide in Co matrix (WC-Co) balls $(6.35 \mathrm{~mm}$ in diameter) were used as a grinding media. $\mathrm{WC}-\mathrm{Co}$ balls are significantly harder and twice heavier than SS balls, therefore increased efficiency of milling is foreseen. Milling conditions are summarized in Table I. Note that balls-to-powder ratio (BPR) is calculated as the ratio of mass of balls divided by the mass of powder. Therefore, using heavy $\mathrm{WC}-\mathrm{Co}$ balls led to doubled BPR, despite the volume of balls and the powder remained the same.

TABLE I

Summary of parameters of milling process. Milling time and speed for batch with WC balls was slightly adjusted for technological reasons.

\begin{tabular}{c|c|c|c|c|c|c}
\hline \hline Sample & $\begin{array}{c}\text { Cooling } \\
\text { liquid }\end{array}$ & $\begin{array}{c}\text { Ball } \\
\text { material }\end{array}$ & BPR & $\begin{array}{c}\text { Milling } \\
\text { speed [rpm] }\end{array}$ & $\begin{array}{c}\text { Milling } \\
\text { time [h] }\end{array}$ & SA [wt.\%] \\
\hline$\# 1$ & LN & SS & $16: 1$ & 700 & $4: 00$ & - \\
$\# 2$ & LN & WC-Co & $32: 1$ & 650 & $3: 15$ & - \\
$\# 3$ & LAr & SS & $16: 1$ & 700 & $4: 00$ & - \\
$\# 4$ & LAr & SS & $16: 1$ & 700 & $4: 00$ & 8 \\
$\# 5$ & LAr & SS & $16: 1$ & 700 & $8: 00$ & 8 \\
$\# 6$ & LAr & WC-Co & $32: 1$ & 650 & $3: 15$ & 8
\end{tabular}


Stearic acid (SA, see Table I) was used as a process control agent to prevent excessive cold-welding in samples \#4-6. The used amount (8 wt\% of powder) was found to be effective in suppressing the cold-welding, but even a smaller amount would suffice. To remove remaining SA adhered to the powder particle surface after milling (and thus reduce the overall contamination), powders were washed in ethanol and filtered using filtration paper three times.

Milled powder was imaged using FEI Quanta 200F (equipped with field emission gun) scanning electron microscope (SEM). Furthermore, for quantitative analysis, powder particles were hot mounted in a synthetic resin, ground and polished using standard metallographic methods and examined on a cross-section using SEM equipped with energy dispersive X-ray spectroscopy (EDS) detector. The amount of light elements $(\mathrm{N}, \mathrm{O}, \mathrm{H})$ was measured by carrier gas hot extraction (CGHE) method. Microhardness of powders was measured semiautomatically by Qness Q10A testing machine using the Vickers method with very low force of $0.002 \mathrm{kgf}$ (HV0.002) to limit the size of the indent. 50 particles of each sample were manually measured.

\section{Results and discussion}

\subsection{Particle size and morphology}

Morphology of the particles was significantly changed by attrition milling from a sphere to the shape of a thin disc or plate (see Fig. 1).

Particle size was analyzed by the Feret diameter (also known as caliper diameter). Maximum and minimum Feret diameter was evaluated for each particle. Acquired statistics were fitted by lognormal distribution and appropriate mean value and standard deviation were obtained. The results are summarized in Table II. The influence of LN was already discussed in [11] and corresponding values are mentioned here for comparison.

Reduction in particle size in LAr milling was generally not observed. However, there is however a strong influence of the material of grinding balls - average particle size and shape after $3: 15 \mathrm{~h}$ of milling by $\mathrm{WC}-\mathrm{Co}$

\section{TABLE II}

Particle size and shape characteristics. Note that standard deviation may be greater than the value itself when fitting lognormal distribution.

\begin{tabular}{c|c|c|c}
\hline \hline Sample & $\begin{array}{c}\text { Max. Feret } \\
\text { diameter }[\mu \mathrm{m}]\end{array}$ & $\begin{array}{c}\text { Min. Feret } \\
\text { diameter }[\mu \mathrm{m}]\end{array}$ & $\begin{array}{c}\text { Aspect } \\
\text { ratio }\end{array}$ \\
\hline initial & $39 \pm 13$ & $33 \pm 14$ & $1.4 \pm 0.4$ \\
$\# 1$ & $103 \pm 88$ & $63 \pm 66$ & $1.9 \pm 0.8$ \\
$\# 2$ & $54 \pm 41$ & $36 \pm 29$ & $1.6 \pm 0.5$ \\
$\# 3$ & $179 \pm 65$ & $124 \pm 69$ & $1.7 \pm 0.6$ \\
$\# 4$ & $98 \pm 72$ & $22 \pm 17$ & $5.5 \pm 6.3$ \\
$\# 5$ & $66 \pm 62$ & $10 \pm 8$ & $10 \pm 16$ \\
$\# 6$ & $60 \pm 66$ & $8 \pm 7$ & $8.7 \pm 8.4$
\end{tabular}

balls (sample \#6) is comparable to the milling using SS balls for $8 \mathrm{~h}$ (sample \#5). It is also observable that reduction of particles size is not saturated after $4 \mathrm{~h}$ using SS balls as manifested by comparing Fig. $1 \mathrm{~b}$ and c. Moreover, equilibrium particle size may have not been achieved even after $8 \mathrm{~h}$, since disc-shaped particles did not undergo fragmentation as suggested in [7].
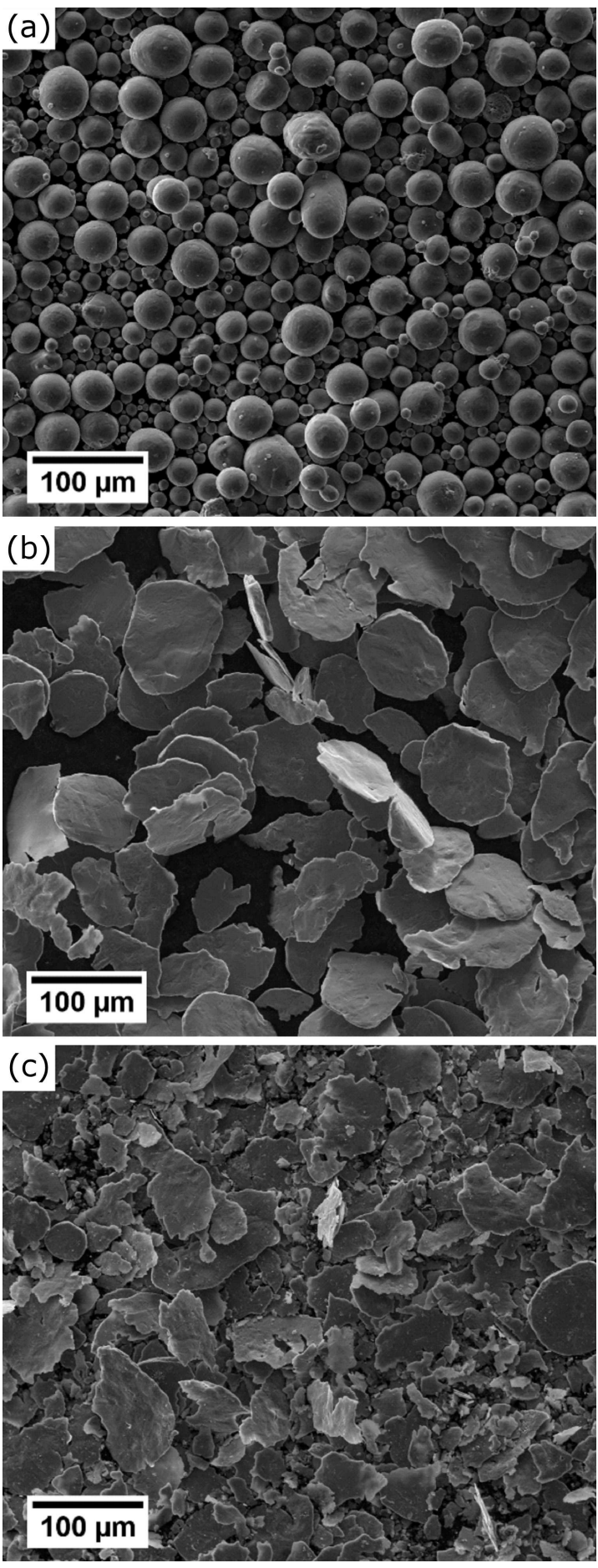

Fig. 1. SEM micrographs of (a) initial powder, (b) powder milled for $4 \mathrm{~h}$ with SS balls, (c) powder milled for 3:15 h with WC-Co balls (both in LAr, with SA). 


\subsection{Contamination}

Contamination is an inevitable problem of powder metallurgy and mechanical milling in particular due to large surface area of particles and formation of new surfaces during process, which is dependent on the milling intensity - the more intensive the milling is (longer duration, heavier balls), the higher the contamination is. Two types of contamination are usually involved - contamination from milling environment and cooling liquid $(\mathrm{H}$, $\mathrm{C}, \mathrm{N}, \mathrm{O})$ and contamination from balls and milling tank ( $\mathrm{Fe}, \mathrm{W}, \mathrm{C}, \mathrm{Co})$.

As observed in Table III, hydrogen contamination has its origin only in the stearic acid (SA) used as the process control agent. Note that cleaning the powder by ethanol reduced the contamination by hydrogen from approximately $1 \mathrm{wt} \%$ to $0.02-0.05 \mathrm{wt} \%$. It is therefore assumed that hydrogen is bonded in stearic acid even after milling and cleaning procedure is efficient in removing excessive stearic acid. The nitrogen concentration is lower when $\mathrm{SA}$ is used and was also reduced during cleaning. This is because SA works as a protective film on a particle surface trapping the nitrogen. The measured nitrogen contamination is significantly lower than that reported by Ertorer et al. [4] ( $0.59 \mathrm{wt} \%$ of $\mathrm{N}$ ) after $8 \mathrm{~h}$ of milling in LAr, which can be caused by different purity of cooling liquid.

TABLE III

Contamination of cleaned powders by CGHE analysis (estimated relative error $5 \%$ ) and Vickers microhardness (HV0.002) of powder particles measured on the crosssection.

\begin{tabular}{c|c|c|c|c}
\hline \hline Sample & $\begin{array}{c}\text { Oxygen } \\
\text { [wt.\%] }\end{array}$ & $\begin{array}{c}\text { Nitrogen } \\
\text { [wt.\%] }\end{array}$ & $\begin{array}{c}\text { Hydrogen } \\
\text { [wt.\%] }\end{array}$ & HV0.002 \\
\hline initial & 0.15 & 0.02 & 0 & $239 \pm 30$ \\
$\# 1$ & 0.43 & 0.80 & 0 & $390 \pm 42$ \\
$\# 2$ & 0.36 & 2.99 & 0 & $484 \pm 66$ \\
$\# 3$ & 0.23 & 0.20 & 0 & $456 \pm 31$ \\
$\# 4$ & 0.36 & 0.06 & 0.051 & $327 \pm 31$ \\
$\# 5$ & 0.38 & 0.02 & 0.015 & $286 \pm 55$ \\
$\# 6$ & 0.59 & 0.08 & 0.029 & $315 \pm 61$
\end{tabular}

Note also that CGHE method measures overall average contamination of powder, while contamination might be very inhomogeneous, presumably higher near the particle surface.

Areal EDS analysis was performed on a particle crosssection to determine concentration of heavier elements. Trace amount of Fe (0.5 wt\% maximum) was detected in all samples and differences between samples were not detected suggesting that Fe is present in the original material, which is common in commercial purity Ti. Small WC-Co particles (approximately $1 \mu \mathrm{m}$ in diameter) were observed on the particle surface of the sample \#6 (Fig. 2). These are fragments of grinding balls which became partially brittle under low temperatures. No WC-Co particles were present within particle interior.

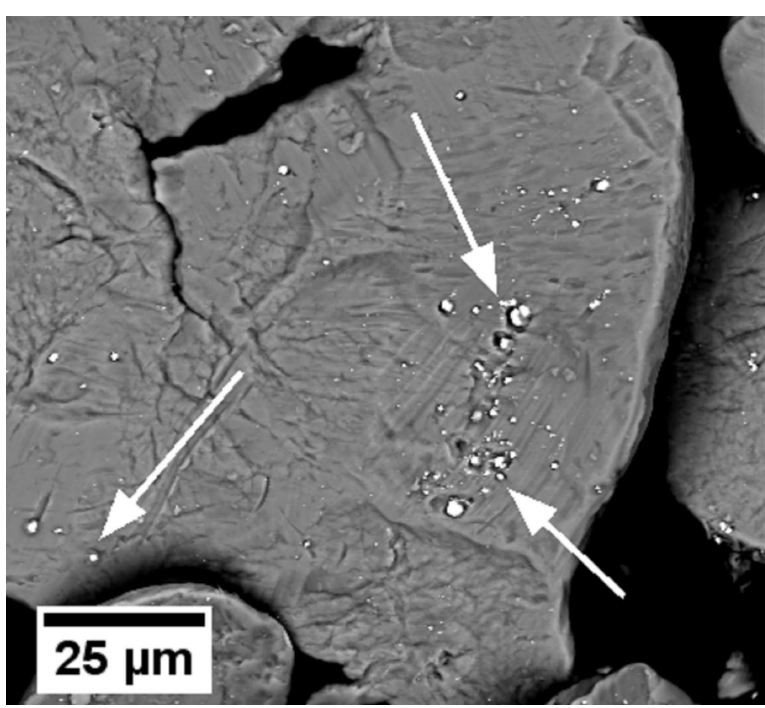

Fig. 2. WC-Co particles (fragments of grinding balls) seen as bright spots (BSE contrast) on the particle surface.

\subsection{Microhardness}

The results of microhardness measurements are shown in Table III. High standard deviation is caused partly by difficulties with indenting small and hard powder particles and subsequent measurement of very small indents. However, it seems that the hardness among particles is not fully homogeneous.

There are two main strengthening factors influencing microhardness of the powder - increased concentration of interstitials (mainly $\mathrm{N}$ and $\mathrm{O}$ ) and dislocation/GB strengthening. Preliminary SEM investigations of milled powders (not presented here) suggest submicrometer grain size, however, the strengthening even in material milled in LAr can be almost fully attributed to increased $\mathrm{O}$ and $\mathrm{N}$ content [12] under assumption of homogeneous distribution of $\mathrm{N}$ and $\mathrm{O}$.

Determination of the effect of microstructural refinement on the hardness would require detailed microstructure observation and eventually utilization of nanoindentation technique, which is beyond the scope of this study.

\section{Conclusions}

Commercially pure titanium powder was processed by cryogenic milling. It can be concluded that:

- Particle morphology is changed during milling from spherical particles to a disc/plate-shaped particles.

- Particle size is reduced only after $8 \mathrm{~h}$ milling when using stainless steel milling balls, while $3: 15 \mathrm{~h}$ is sufficient for particle size reduction when $\mathrm{WC}-\mathrm{Co}$ balls are used.

- Milling with WC-Co balls is approximately twice as effective for particle size reduction, but at the expense of increased contamination. 
- Microhardness of all samples increased after milling as a result of contamination by nitrogen and oxygen and due to the dislocation/grain boundary strengthening.

\section{Acknowledgments}

This work was supported by Czech Science Foundation under the grant GACR 17-20700Y. M.J. and P.H. acknowledge financial support by the ERDF under the project CZ.02.1.01/0.0/0.0/15_003/0000485.

\section{References}

[1] T.G. Langdon, Acta Mater. 61, 7035 (2013).

[2] A.A. Popov, I.Y. Pyshmintsev, S.L. Demakov, A.G. Illarionov, T.C. Lowe, A.V. Sergeyeva, R.Z. Valiev, Scr. Mater. 37, 1089 (1997).

[3] A.P. Zhilyaev, T.G. Langdon, Prog. Mater. Sci. 53, 893 (2008).
[4] O. Ertorer, A. Zúńiga, T. Topping, W. Moss, E.J. Lavernia, Metall. Mater. Trans. A 40, 91 (2008).

[5] O. Ertorer, T. Topping, Y. Li, W. Moss, E.J. Lavernia, Scr. Mater. 60, 586 (2009).

[6] O. Ertorer, T.D. Topping, Y. Li, W. Moss, E.J. Lavernia, Metall. Mater. Trans. A 42, 964 (2011).

[7] C. Suryanarayana, Prog. Mater. Sci. 46, 1 (2001).

[8] D.B. Witkin, E.J. Lavernia, Prog. Mater. Sci. 51, 1 (2006).

[9] F. Sun, P. Rojas, A. Zúńiga, E.J. Lavernia, Mater. Sci. Eng. A 430, 90 (2006).

[10] S.S. Dheda, C. Melnyk, F.A. Mohamed, Mater. Sci. Eng. A 584, 88 (2013).

[11] J. Kozlik, H. Becker, J. Strasky, P. Harcuba, M. Janecek, in: Met. 2016 25th An niv. Int. Conf. Metall. Mater., TANGER Ltd, Ostrava 2016, p. 1439.

[12] H.R. Ogden, R.I. Jaffe, Effects of Carbon, Oxygen, and Nitrogen on Mechanical Properties of Titanium and Titanium Alloys, Titanium Metallurgical Laboratory, Battelle Memorial Institute, Columbus $(\mathrm{OH})$ 1955. 